\title{
Fbxw7 Limits Myelination by Inhibiting mTOR Signaling
}

\author{
Christina A. Kearns, $₫$ Andrew M. Ravanelli, Kirsten Cooper, and Bruce Appel \\ Department of Pediatrics, University of Colorado School of Medicine, Aurora, Colorado 80045
}

An important characteristic of vertebrate CNS development is the formation of specific amounts of insulating myelin membrane on axons. CNS myelin is produced by oligodendrocytes, glial cells that extend multiple membrane processes to wrap multiple axons. Recent data have shown that signaling mediated by the mechanistic target of rapamycin (mTOR) serine/threonine kinase promotes myelination, but factors that regulate mTOR activity for myelination remain poorly defined. Through a forward genetic screen in zebrafish, we discovered that mutation of $f b x w 7$, which encodes the substrate recognition subunit of a SCF ubiquitin ligase that targets proteins for degradation, causes hypermyelination. Among known Fbxw7 targets is mTOR. Here, we provide evidence that mTOR signaling activity is elevated in oligodendrocyte lineage cells of $f b x w 7$ mutant zebrafish larvae. Both genetic and pharmacological inhibition of mTOR function suppressed the excess myelin gene expression resulting from loss of Fbxw7 function, indicating that mTOR is a functionally relevant target of $\mathrm{Fbxw} 7$ in oligodendrocytes. $f b x w 7$ mutant larvae wrapped axons with more myelin membrane than wild-type larvae and oligodendrocyte-specific expression of dominant-negative Fbxw7 produced longer myelin sheaths. Our data indicate that Fbxw7 limits the myelin-promoting activity of mTOR, thereby serving as an important brake on developmental myelination.

Key words: Fbxw7; glia; mTOR; myelin; oligodendrocyte; zebrafish

\section{Significance Statement}

Myelin, a specialized, proteolipid-rich membrane that ensheaths and insulates nerve fibers, facilitates the rapid conduction of electrical impulses over long distances. Abnormalities in myelin formation or maintenance result in intellectual and motor disabilities, raising a need for therapeutic strategies designed to promote myelination. The mTOR kinase is a powerful driver of myelination, but the mechanisms that regulate mTOR function in myelination are not well understood. Our studies reveal that Fbxw7, a subunit of a ubiquitin ligase that targets other proteins for degradation, acts as a brake on myelination by limiting mTOR function. These findings suggest that Fbxw7 helps tune the amount of myelin produced during development and raise the possibility that Fbxw7 could be a target of myelin-promoting therapies.

\section{Introduction}

By tightly ensheathing axons, myelin membrane facilitates rapid conduction of electrical impulses and maintains axon health. In the CNS, myelin is produced by oligodendrocytes, glial cells that extend multiple membrane processes to wrap multiple axons. The unique physiological properties of myelin membrane result

Received Dec. 6, 2014; revised Sept. 24, 2015; accepted Sept. 29, 2015.

Author contributions: B.A. designed research; C.A.K., A.M.R., and K.C. performed research; A.M.R. contributed unpublished reagents/analytic tools; C.A.K. and B.A. analyzed data; B.A. wrote the paper.

This work was supported by the National Institutes of Health (NIH Grant R01 NS046668 to B.A., National Cancer Institute Grant 5T32CA08208613 to A.M.R.) and the Gates Frontiers Fund. The University of Colorado Anschutz Medical Campus Zebrafish Core Facility is supported by NIH Grant P30 NS048154. The electron micrographs were generated in the EM core facility of the Department of Cell and Developmental Biology, which is supported by NIH Grant P30 NS048154. We thank Xiaolei Xu (Mayo Clinic College of Medicine) for the gift of mtor mutant fish, Kristen Kwan (University of Utah) for the gift of Gateway plasmids, Dot Dill for EM technical support, and members of the Appel laboratory and Wendy Macklin (University of Colorado School of Medicine) for critical feedback on this project.

The authors declare no competing financial interests.

Correspondence should be addressed to Bruce Appel, Department of Pediatrics, University of Colorado Anschutz Medical Campus, MS 8108, Aurora, C0 80045. E-mail: bruce.appel@ucdenver.edu.

DOI:10.1523/JNEUROSCI.4968-14.2015

Copyright $\odot 2015$ the authors $\quad 0270-6474 / 15 / 3514861-11 \$ 15.00 / 0$ from combination of myelin-specific proteins and enrichment of certain lipids such as cholesterol. Therefore, the formation of myelin membrane requires mechanisms that coordinate the production of large amounts of myelin proteins and lipids.

One key driver of CNS myelination is the Akt and mTOR kinase signaling pathway. Pharmacological inhibition of mTOR in vitro using rapamycin reduced the expression of myelin gene transcripts and proteins (Tyler et al., 2009; Guardiola-Diaz et al., 2012) and diminished the levels of proteins necessary for cholesterol synthesis (Tyler et al., 2011). Consistent with this, spinal cords of mice in which $m$ TOR gene function was inactivated in oligodendrocytes were hypomyelinated (Wahl et al., 2014). Conversely, oligodendrocyte-specific expression of constitutively active Akt, a serine/threonine kinase that can activate mTOR, drove formation of excess myelin (Flores et al., 2008). Hypermyelination was blocked by rapamycin, indicating that Akt promotes myelin formation by activating mTOR (Narayanan et al., 2009).

What factors influence mTOR signaling activity in myelination? Akt and mTOR are activated by signals transduced from receptor tyrosine kinases via formation of phosphatidylinositol 
3,4,5-triphosphate (PIP3) from phosphatidylinositol 4,5 biphosphate (PIP2) by phosphoinositide 3-kinase (PI3K). Candidate activating pathways include those mediated by insulin growth factor (Carson et al., 1993; Goddard et al., 1999; Ye et al., 2002) and Neuregulin-1 (Brinkmann et al., 2008; Makinodan et al., 2012). Pathway activity is antagonized by the phosphatase and tensin homolog (PTEN), which converts PIP3 to PIP2, and oligodendrocyte-specific inactivation of PTEN caused hypermyelination (Goebbels et al., 2010; Harrington et al., 2010). Therefore, the amount of myelin formed in the CNS may be determined, in part, by the balance of positive and negative regulators of the PIP3/Akt/mTOR pathway. Additional regulators of pathway activity that modulate CNS myelination have not yet been described.

In a forward genetic screen in zebrafish, we identified a mutation disrupting $\mathrm{Fbxw} 7$, the substrate recognition subunit of a SCF ubiquitin ligase, which caused the formation of excess oligodendrocyte lineage cells (Snyder et al., 2012). We attributed specification of excess oligodendrocytes to elevated activities of Notch receptors, known targets of Fbxw7-mediated degradation (Hubbard et al., 1997; Gupta-Rossi et al., 2001; Oberg et al., 2001). We noted that $f b x w 7$ mutant larvae appeared also to have ectopic and excess myelin gene expression. Because Notch signaling is inhibitory to myelin gene expression (Wang et al., 1998; Genoud et al., 2002; Givogri et al., 2002; John et al., 2002; Park and Appel, 2003), we reasoned that Fbxw7 must target a positive regulator of myelination for degradation. Because Fbxw7 targets mTOR for degradation in cancer cells (Mao et al., 2008), we hypothesized that Fbxw7 limits myelination by limiting the amount of mTOR available to promote myelination. Here, we present tests of this hypothesis and provide evidence that Fbxw7 modulates myelination by negatively regulating mTOR signaling activity.

\section{Materials and Methods}

Ethics statement. The animal work in this study was approved by the Institutional Animal Care and Use Committees of the University of Colorado School of Medicine.

Zebrafish lines and husbandry. Embryos were raised at $28.5^{\circ} \mathrm{C}$ in egg water or embryo medium and staged according to hours postfertilization (hpf), days postfertilization (dpf), and morphological criteria (Kimmel et al., 1995). Zebrafish lines used for this study included $f b x w 7^{\mathrm{vu} 56}$ (Snyder et al., 2012), mtor ${ }^{\text {xu015Gt }}$ (Ding et al., 2011), and $\operatorname{Tg}($ olig2:EGFP) vu12 (Shin et al., 2003).

In situ RNA hybridization and immunohistochemistry. plp1a, mbp (Brösamle and Halpern, 2002), and cldnk (Takada and Appel, 2010) RNA probes were generated using digoxigenin RNA labeling kits (Roche). In situ RNA hybridization was performed as described previously (Hauptmann and Gerster, 2000). For immunohistochemistry, larvae were fixed using $4 \%$ paraformaldehyde, embedded, frozen, and sectioned using a cryostat microtome as described previously (Park and Appel, 2003). We used rabbit anti-Sox10 (Park et al., 2005), rabbit anti-Mbp (Kucenas et al., 2009), rabbit anti-phospho-S6 (Cell Signaling Technology, catalog \#2215), mouse anti-GFP (Life Technologies, catalog \#A-11120, 1:100), and anti-rabbit activated Caspase 3 (Abcam, catalog \#13847) as primary antibodies. For fluorescent detection of antibody labeling, we used Alexa Fluor 568 goat anti-rabbit and goat anti-mouse conjugates (1:1000; Life Technologies). To stain myelin, we used FluoroMyelin Red (Life Technologies, catalog \#F34652). In situ hybridization images were collected using a QImaging Retiga Exi color CCD camera mounted on a compound microscope and imported into Adobe Photoshop. Image manipulations were limited to levels, curve, and contrast adjustments. Fluorescence images were collected using a Zeiss Axiovert 200 microscope equipped with a PerkinElmer spinning disk confocal system and Volocity software and imported into Adobe Photoshop.

Genotyping. mtor mutant embryos were genotyped by digesting a small piece of tail tissue in lysis buffer with $1 \mu \mathrm{g} / \mu \mathrm{l}$ proteinase $\mathrm{K}$ at $55^{\circ} \mathrm{C}$, followed by PCR amplification using the following primers: forward primer: 5'-ATAAGAAAAGAAACCACATGTCATACC-3'; reverse primer: 5' -CTTACCACTCAGAGAGACCAAAG-3'; 5'LTR primer: 5' -CCCTA AGTACTTGTACTTTCACTTG-3'.

Plasmid construction. The plasmid pEXPR-Tol2-sox10:DN-fbxw7-2AEGFP-CaaX;Cryaa:Cerulean was constructed using the oligonucleotide primers $5^{\prime}$-TGAGGAGAGGAGACCTCAAGTC-3' and 5' -CTTCATG TCCACGTCAAAGTCC- $3^{\prime}$ to amplify from zebrafish cDNA a $f b x w 7$ fragment encoding aa 419-761 of XP_005171005.1 (predicted F-box/ WD repeat-containing protein 7 isoform $\mathrm{X} 3$ ). This fragment includes the last five coding exons and includes the WD40 repeat domain but excludes the F-box. This was cloned into the Gateway pME vector (Kwan et al., 2007) and then used to create a fusion proprotein with EGFP-CaaX following the viral $2 \mathrm{~A}$ peptide linker, combined with an $\sim 8.2 \mathrm{~kb}$ fragment of sox 10 regulatory DNA (Carney et al., 2006). The plasmid pEXPRTol2-sox10:EGFP-CaaX was also created with the Gateway system and the same sox 10 fragment.

Quantitative PCR. RNA was isolated from 20 pooled larvae for each control or experimental condition. RNA isolation for each experiment was performed in triplicate. Reverse transcription was performed using iScript Reverse Transcriptase Supermix (Bio-Rad, catalog \#170-8840). Real-time qPCR was performed in triplicate for each cDNA sample using an Applied Biosystems StepOne Plus machine and software version 2.1. Taqman Gene Expression assays (Applied Biosystems) were used to detect mpz (Dr03131917_m1), 36k (Dr03438574_g1), hmgcs1 (Dr03 107119_m1), fdps (Dr03424631_g1), hmgcra (Dr034228703_m1), and rpl13a (Dr03101115_g1) as the endogenous control. A custom-designed Taqman assay to detect $m b p$ included the primers $m b p$ - "A" forward, 5'GTTCTTCGGAGGAGACAAGAAGAG-3'; $m b p$ "A" reverse, 5'GTCTCTGTGGAGAGGAGGATAGATGA-3'; and $m b p$-“a” probe, $5^{\prime}$ AAGGGAAAGGGTTCATT-3'.

Drug inhibitor and rescue experiments. Rapamycin (R-5000; LC Laboratories) was resuspended in dimethyl-sulfoxide (DMSO) to a stock concentration of $10 \mathrm{~mm}$, aliquoted, and stored at $-20^{\circ} \mathrm{C}$. Embryos were treated from 72 to $96 \mathrm{hpf}$ for qPCR experiments and from 3 to $7 \mathrm{dpf}$ for Western blot analysis and incubated at $28.5^{\circ} \mathrm{C}$ in a water bath of $10 \mu \mathrm{M}$ rapamycin and $0.1 \%$ DMSO in embryo medium. DMSO control groups were treated with $0.1 \%$ DMSO in embryo medium. For assessment of oligodendrocyte lineage cell number, $f b x w 7^{-1-} ; \operatorname{Tg}($ olig2:EGFG) larvae were imaged at 72 or $96 \mathrm{hpf}$ on a confocal microscope using a $20 \times$ objective, placed individually in dishes, treated for $24 \mathrm{~h}$ with DMSO or rapamycin, and then imaged again. Dorsal olig2:EGFP ${ }^{+}$cells were counted in confocal stacks spanning three or six somite hemisegments at the level of the trunk spinal cord.

$E M$. At $8 \mathrm{dpf}$, zebrafish larvae were anesthetized with Tricaine and fixed in a solution of paraformaldehyde, glutaraldehyde, and sodium cacodylate, followed by osmium fixation using osmium tetroxide and sodium cacodylate as described previously (Langworthy and Appel, 2012). Reagents were purchased from Electron Microscopy Sciences. Sixty-nanometer sections were imaged on an FEI Technai Biotwin microscope with a Gatan Ultrascan camera.

Western blotting. Protein lysates were prepared in RIPA buffer, protease inhibitors, and phosphatase inhibitors (Roche) from $7 \mathrm{dpf}$ pooled larvae from each drug treatment and genotype. $20 \mu \mathrm{g}$ samples were loaded into a $4-20 \%$ gel (Bio-Rad). After transfer, the membrane was blocked in 5\% BSA in TBST, followed by overnight incubation at $4^{\circ} \mathrm{C}$ with rabbit anti-pS6 antibody at 1:1000 (Cell Signaling Technology, catalog \#2215). Membranes were stripped and reprobed for total S6 using mouse anti-S6 antibody (Cell Signaling Technology, catalog \#1217, 1:1000). Goat anti-rabbit HRP (Pierce, catalog \#1858415) and goat antimouse HRP secondary antibodies (Pierce, catalog \#1858413) were applied at 1:10,000 for $1 \mathrm{~h}$ at room temperature. Blots were developed using an ECL kit (Pierce, catalog \#34076) and imaged on film.

\section{Results}

\section{Fbxw7 inhibits myelin gene expression and myelination}

We reported previously that expression of constitutively active Notchla produced excess oligodendrocyte progenitor cells (OPCs) (Park and Appel, 2003). Consistent with this finding, we 
subsequently showed that $f b x w 7$ mutant zebrafish larvae produce excess oligodendrocyte lineage cells as a consequence of elevated Notch signaling activity (Snyder et al., 2012). However, whereas expression of constitutively active Notchla after OPC formation blocked myelin gene expression (Park and Appel, 2003), fbxw7 mutant larvae expressed myelin genes at a high level (Snyder et al., 2012). If Fbxw7 limits Notch signaling activity and Notch inhibits myelin gene expression, how do $f b x w 7$ mutant larvae express myelin genes? One possibility is that Fbxw7 also inhibits activity of positive regulators of myelination and that, in the absence of Fbxw7, these factors overcome the inhibitory effect of Notch. To begin to test this idea, we first characterized myelination in $f b x w 7^{\text {vu56 }}$ mutant larvae in greater detail. At $4 \mathrm{dpf}$, wildtype larvae expressed $p l p 1 a, c l d n k$, and $m b p$ near the pial surface of ventral and dorsal spinal cord (Fig. $1 A-C$ ). The spatial distributions of transcripts in $f b x w 7$ mutant larvae were mostly similar to that of wild-type (Fig. 1D-F) except that, as we noted previously (Snyder et al., 2012), cells within the medial portion of spinal cord sometimes expressed plp1a and cldnk (Fig. 1D,E; see Fig. $3 B, F)$. In addition, although processed similarly and simultaneously, staining of hybridization products appeared more intense in mutant larvae compared with wild-type, suggesting that myelin genes were expressed at higher levels in the absence of $f b x w 7$ function. qPCR supported this observation, revealing significantly higher levels of $m b p$ and CNS-specific $m p z$ and $36 k$ transcripts (Fig. 1G). Because myelin membrane is enriched for particular lipids, especially cholesterol (Horrocks, 1967), we also measured expression of genes that encode enzymes of the cholesterol biosynthesis pathway. Similar to myelin protein-encoding transcripts, fdps, $h m g c r a$, and $h m g c s 1$ transcript levels were elevated in $f b x w 7$ mutant larvae compared with wild-type (Fig. $1 H$ ). Consistent with these results, levels of Mbp, detected by immunohistochemistry, and myelin, detected by Fluoromyelin staining, appeared elevated in $f b x w 7$ mutant larvae compared with wild-type (Fig. 1I-L). Furthermore, EM revealed that myelinated axons in the ventral spinal cord of $8 \mathrm{dpf} f b x w 7$ mutant larvae averaged $\sim 2$ more turns of myelin membrane than those of similar size in wild-type larvae (Fig. 1M-O). Because larger axons typically have thicker myelin, we also determined the crosssectional area of myelinated axons in wild-type and $f b x w 7$ mutant larvae. Myelinated ventral spinal cord axons of $f b x w 7$ mutant larvae were larger than those of wild-type, averaging $0.73 \mu \mathrm{m}^{2}$ compared with $0.49 \mu \mathrm{m}^{2}$ ( $n=67$ axons in 3 larvae for each genotype; $p=0.0032$, two-tailed Mann-Whitney test). Although the size distributions of axons overlapped in larvae of both genotypes, $f b x w 7$ mutant larvae had fewer small axons and more large axons that were myelinated than wild-type (Fig. $1 P$ ). We conclude that $f b x w 7$ mutant larvae produce excess oligodendrocytes accompanied by elevated expression of myelin genes and thicker myelin sheaths.

\section{Fbxw7 limits myelination via negative regulation of mTOR}

What myelin-promoting factors could be negatively regulated by Fbxw7? Among known Fbxw7 targets is mTOR (Mao et al., 2008), a positive regulator of myelination in rodent models (Tyler et al., 2009; Guardiola-Diaz et al., 2012; Bercury et al., 2014; Lebrun-Julien et al., 2014; Wahl et al., 2014). To investigate the possibility that Fbxw7 regulates mTOR in myelination, we first tested whether mTOR promotes myelination in zebrafish as it does in mice. To do so, we examined oligodendrocyte development and myelination in larvae homozygous for the $m$ tor ${ }^{\mathrm{xu} 015 \mathrm{Gt}}$ mutant allele, which nearly eliminates mTOR protein (Ding et al., 2011). We first assessed oligodendrocyte lineage cell forma- tion and distribution by labeling tissue sections obtained from 4 dpf larvae with antibody to detect Sox 10, which marks both OPCs and myelinating oligodendrocytes. Sox $10^{+}$cells occupied similar positions in wild-type and mtor mutant larvae (Fig. $2 A, B$ ), indicating that mtor function is not necessary for OPC specification and migration. However, $4 \mathrm{dpf}$ mutant larvae had slightly fewer Sox $10^{+}$cells than wild-type larvae (Fig. 2C).

We next examined myelin gene expression using in situ RNA hybridization. In contrast to wild-type (Fig. $2 D-F$ ) and $f b x w 7$ mutants (Fig. $1 D-F)$, mtor mutant larvae appeared to express plp $1 a, c l d n k$, and $m b p$ transcripts at a low level (Fig. 2G-I). Quantitative PCR confirmed these observations, revealing $>2$-fold reductions in transcript levels compared with wild-type (Fig. $2 J$ ). Because mTOR promotes cholesterol biosynthetic pathway gene expression via activation of the SREBP2 transcription factor, we also quantified fdps, hmgcsl, and hmgcra transcript levels and found them to be substantially lower in mtor mutant larvae relative to wild-type (Fig. $2 K$ ). Consistent with the low level of myelin gene transcripts, anti-Mbp and fluoromyelin staining revealed barely detectable levels of myelin proteins in mtor mutant larvae (Fig. 2L-O). Furthermore, EM revealed that myelin sheaths on CNS axons were thinner in mtor mutant larvae relative to axons of similar size in wild-type (Fig. 2P,Q), averaging 2.5 myelin membrane wraps compared with the wild-type average of 3.2 wraps $(n=3$ larvae and 30 axons for wild-type and 3 larvae and 8 axons for mtor mutants; $p<0.0001$, two-tailed unpaired $t$ test; analysis limited to axons with a cross-sectional area of $0.401-3.0$ $\mu \mathrm{m}^{2}$ ). Myelinated axons of mtor mutant larvae were smaller than those of wild-type larvae, averaging $0.29 \mu \mathrm{m}^{2}$ compared with $0.49 \mu \mathrm{m}^{2}(n=3$ larvae and 67 axons for wild-type and 3 larvae and 66 axons for mutant; $p=0.0002$, two-tailed Mann-Whitney test). Analysis of size distribution revealed that mtor mutant larvae had more small, myelinated axons and fewer large, myelinated axons than wild-type (Fig. 2R). Altogether, these data indicate that $\mathrm{mTOR}$ is a positive regulator of myelination in zebrafish, as it is in rodents.

If the loss of Fbxw7 function results in excess myelination because of elevated mTOR activity, then genetic or pharmacological reduction of mTOR activity should reverse the hypermyelination phenotype of $f b x w 7$ mutant larvae. To test this, we first examined oligodendrocyte lineage cell number in larvae lacking both Fbxw7 and mTOR functions. Whereas fbxw 7 mutant larvae had an $\sim 2$-fold excess of Sox $10^{+}$cells relative to wild-type, $f b x w 7^{-1-} ; m$ tor ${ }^{-1-}$ mutant larvae had only a slight excess of oligodendrocyte lineage cells (Fig. $3 A$ ). $f b x w 7^{-1-}$ mutant larvae treated with rapamycin from 3 to 4 $\mathrm{dpf}$ also had fewer Sox $10^{+}$cells than untreated mutants, but more than untreated wild-type larvae (Fig. 3A). To investigate the reason for this difference in number, we counted dorsally migrated olig2:EGFP ${ }^{+}$oligodendrocyte lineage cells in living 3 $\operatorname{dpf} f b x w 7^{-1-}$ larvae, incubated them individually in rapamycin for $24 \mathrm{~h}$, and recounted the cells. Whereas the number of oligodendrocyte lineage cells increased $42 \%$ in untreated control larvae, the number in rapamycin-treated larvae increased $15 \%$ (Fig. $3 B$ ). Treating $f b x w 7^{-1}$ larvae with rapamycin from 4 to $5 \mathrm{dpf}$ did not change oligodendrocyte lineage cell number (Fig. 3B). To determine whether the smaller increase between 3 and $4 \mathrm{dpf}$ resulted from cell death in rapamycin-treated larvae, we again incubated $f b x w 7^{-1-}$ larvae with rapamycin from 3 to $4 \mathrm{dpf}$ and performed immunohistochemistry to detect activated Caspase 3. This revealed no difference in oligodendrocyte lineage cell death in control and rapamycintreated larvae ( $n=10$ larvae for each condition). 


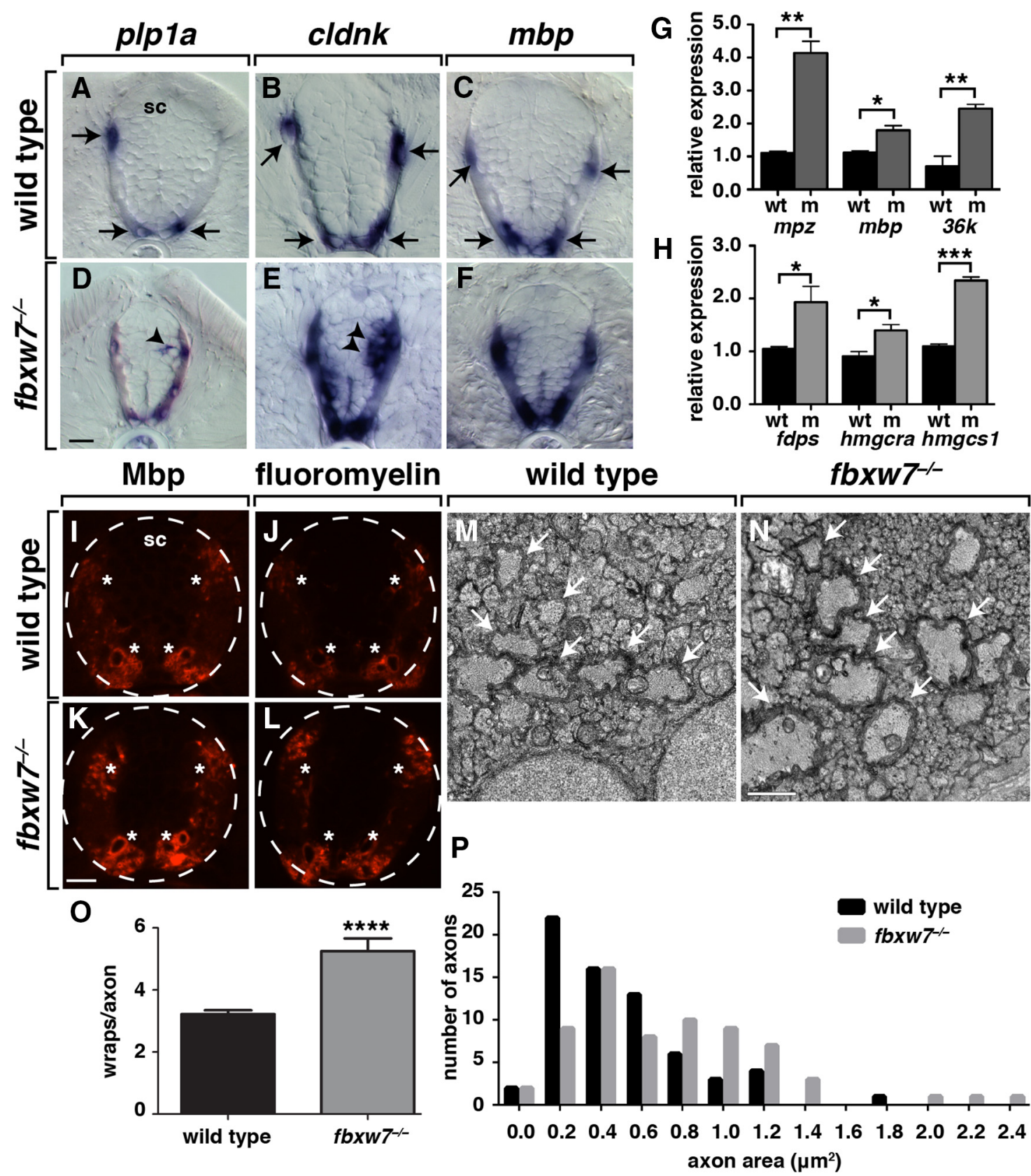

Figure 1. Fbxw7 negatively regulates myelination. $\boldsymbol{A}-\boldsymbol{F}$, Transverse sections of 4 dpf larvae at the level of the trunk spinal cord (sc), with dorsal up, processed for in situ RNA hybridization to detect myelin gene expression. Wild-type larvae express plp1a, cldnk, and mbp in cells (arrows) adjacent to the pial surface of dorsal and ventral spinal cord ( $\boldsymbol{A}-\boldsymbol{C}$ ). fbxw 7 mutant larvae express $p / p 1 a$ and cldnk ectopically (arrowheads; $\boldsymbol{D}, \boldsymbol{E}$ ) and cldnk and $m b p$ expression appears elevated $(\boldsymbol{E}, \boldsymbol{F})$. Scale bar, $10 \mu \mathrm{m} . \boldsymbol{G}, \boldsymbol{H}$, Graphs showing relative levels of myelin gene $(\boldsymbol{G})$ and cholesterol pathway gene $(\boldsymbol{H})$ transcripts in $4 \mathrm{dpf}$ wild-type (wt) and fbxw7 mutant (m) larvae measured by qPCR. $n=3$ biological replicates consisting of 20 larvae for each measurement. ${ }^{*} p<0.05$, ${ }^{* *} p<0.01,{ }^{* * * *} p<$ 0.005 , two-tailed Mann-Whitney test. Error bars indicate SEM. $\boldsymbol{I}-\boldsymbol{L}$, Transverse sections of $7 \mathrm{dpf}$ wild-type and fbxw 7 mutant larvae processed to reveal Mbp by immunohistochemistry $(\boldsymbol{I}, \boldsymbol{K})$ and myelin using Fluoromyelin staining $(\boldsymbol{J}, \boldsymbol{L})$. Dashed circles outline the spinal cord. Processing was performed in parallel and images acquired using identical exposure settings. In wild-type, myelin proteins are mostly localized to dorsal and ventral longitudinal axon tracts (asterisks). Myelin protein labeling appears brighter in $f b x w 7$ mutant sections than in corresponding wild-type sections. Scale bar, $10 \mu \mathrm{m} . M, N$, Electron micrographs of transverse ventral spinal cord sections from $8 \mathrm{dpf}$ wild-type and mutant larvae. Arrows indicate myelinated axons. Scale bar, $1 \mu \mathrm{m} . \mathbf{0}$, Graph showing average number of myelin membrane wraps ensheathing axons in $8 \mathrm{dpf}$ wild-type and $f b x w 7$ mutant larvae. $n=3$ larvae for each genotype. ${ }^{* * * *} p<0.0001$, unpaired two-tailed Student's $t$ test. Error bars indicate SEM. Only axons with a cross-sectional area of $0.401-3.0 \mu \mathrm{m}^{2}$ were used for this analysis. $\boldsymbol{P}$, Graph showing the size distribution of wild-type and mutant myelinated axons in ventral spinal cord of 8 dpf larvae.

We also tested myelin gene expression in larvae lacking both Fbxw7 and mTOR functions. By in situ RNA hybridization, expression levels of $p l p 1 a, c l d n k$, and $m b p$ in $f b x w 7^{-1-} ; m t o r^{-1-}$ mutant larvae appeared to be substantially reduced relative to fbxw7 single mutants and more similar to levels detected in $m$ tor single mutants (Fig. $3 B-M$ ). In addition, double mutant larvae did not ectopically express plpla and $c l d n k$, providing evidence that the ectopic expression in $f b x w 7$ mutant larvae results from misregulated mTOR activity. Consistent with these observations, immunohistochemistry revealed that Mbp expression also was much lower in $f b x w 7^{-1-} ; m t o r^{-1-}$ larvae than in $f b x w 7^{-1-}$ larvae (Fig. $3 N-Q$ ).

To validate these observations, we performed qPCR using rapamycin treatments to interfere with mTOR activity. Wild- 

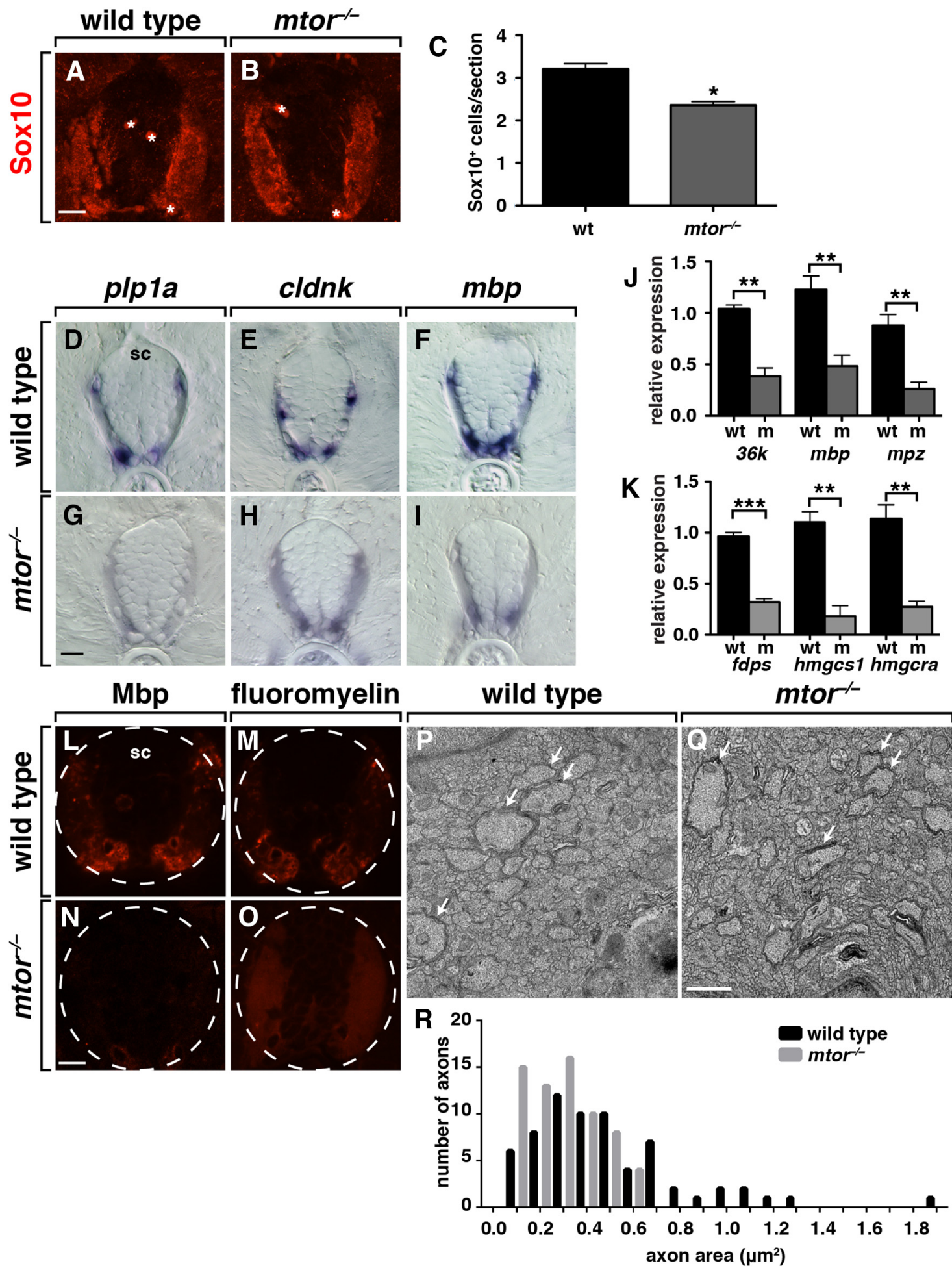

Figure 2. mTOR positively regulates myelination. $A, B$, Transverse sections of 4 dpf larvae at the level of the trunk spinal cord, with dorsal up, processed for immunohistochemistry to detect $S 0 x 10$ expression marking oligodendrocyte lineage cells (asterisks). Scale bar, $10 \mu \mathrm{m}$. C, Graph showing number of Sox $10^{+}$cells in wild-type (wt) and $m$ tor mutant larvae. ( $n=10$ larvae for each genotype; $p=0.0138$, unpaired two-tailed Student's $t$ test). Error bars indicate SEM. $\boldsymbol{D}-\boldsymbol{I}$, Transverse sections of $4 \mathrm{dpf}$ larvae at the level of the trunk spinal cord. Compared with wild-type $(\boldsymbol{D}-\boldsymbol{F})$, myelin gene expression appears weak in mtor mutant larvae $(\boldsymbol{G}-\boldsymbol{I})$. Scale bar, $10 \mu \mathrm{m} . J, \boldsymbol{K}$, Graphs showing relative levels of myelin gene $(\boldsymbol{J})$ and cholesterol pathway gene $(\boldsymbol{K})$ transcripts in 4 dpf wild-type (wt) and mtor mutant (m) larvae measured by qPCR. $n=3$ biological replicates consisting of 20 larvae for each measurement; ${ }^{*} p<0.05$, ${ }^{* *} p<0.01$, ${ }^{* * *} p<0.005$ two-tailed Mann-Whitney test. Error bars indicate SEM. $\mathbf{L}-\mathbf{0}$, Transverse sections of $7 \mathrm{dpf}$ wild-type and mtor mutant larvae processed to reveal Mbp by immunohistochemistry $(\boldsymbol{L}, \boldsymbol{N})$ and myelin using Fluoromyelin staining $(\boldsymbol{M}, \mathbf{0})$. Dashed circles outline the spinal cord (sc). Processing was performed in parallel and images acquired using identical exposure settings. Scale bar, $10 \mu \mathrm{m}$. $\boldsymbol{P}, \boldsymbol{Q}$, Electron micrographs of transverse ventral spinal cord sections from $8 \mathrm{dpf}$ wild-type and mutant larvae. Arrows indicate myelinated axons. Scale bar, $1 \mu \mathrm{m}$. $\boldsymbol{R}$, Graph showing the size distribution of wild-type and mutant myelinated axons in ventral spinal cord of 8 dpf larvae. 

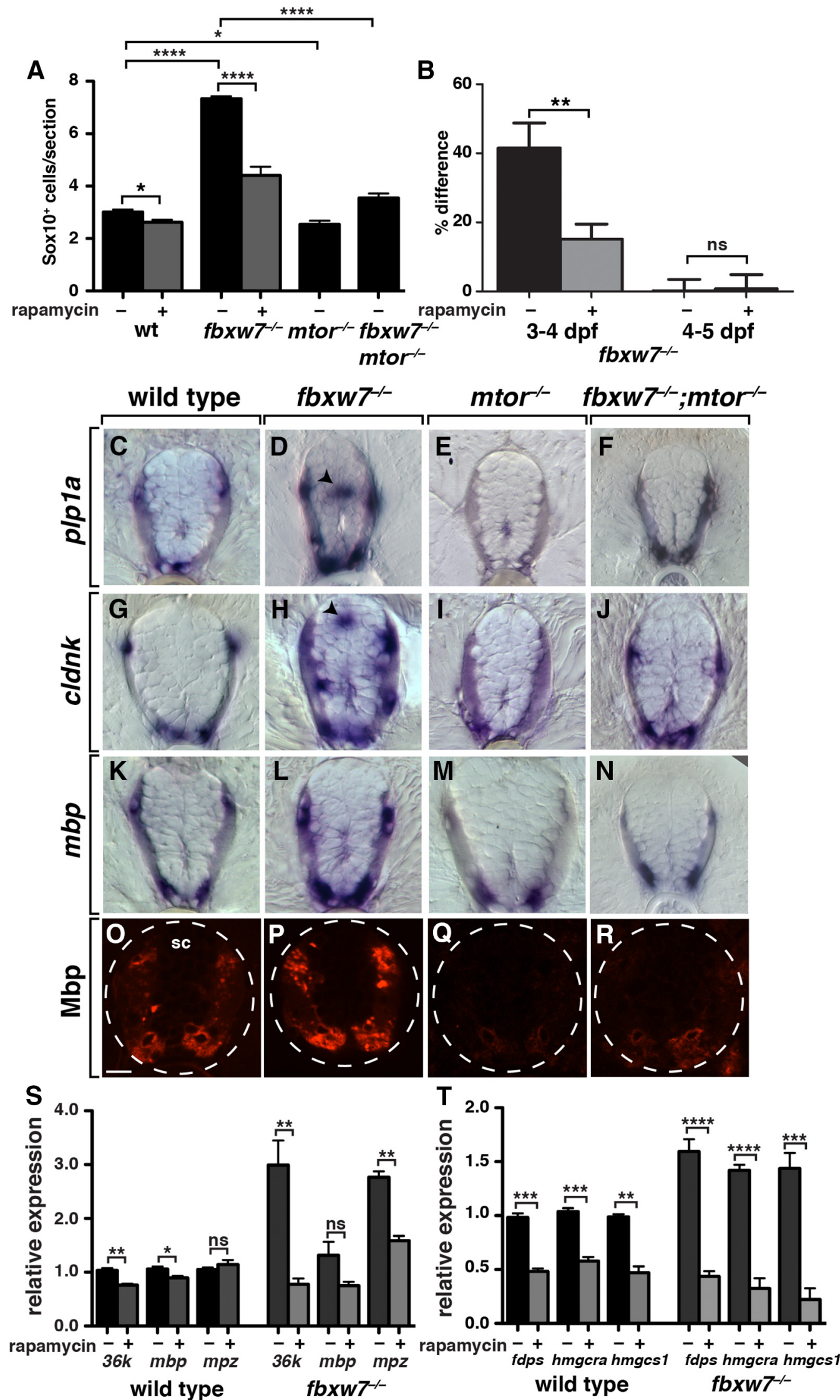

Figure 3. mTOR is required for the excess myelination of $f b x w 7$ mutant larvae. $A$, Graph showing number of Sox $10^{+}$oligodendrocyte lineage cells in 4 dpf control, mutant, and rapamycin-treated larvae. $n=10$ larvae for each group. ${ }^{*} p<0.05,{ }^{* * * *} p<0.0001$, unpaired two-tailed Student's $t$ test. Error bars indicate SEM. $\boldsymbol{B}$, Graph showing percent change in dorsal olig2:EGFP ${ }^{+}$0PCs in foxw $7^{-1-}$ control and rapamycin-treated larvae between 3 and $4 \mathrm{dpf}$ and 4 and $5 \mathrm{dpf} . n=9$ larvae each for $3-4 \mathrm{dpf}$ and 8 larvae each for $4-5 \mathrm{dpf}$. (Figure legend continues.) 
type larvae treated with rapamycin from 72 to $96 \mathrm{hpf}$ expressed the myelin genes $36 k$ and $m b p$ at lower levels than wild-type controls, although $m p z$ levels were not changed (Fig. $3 S$ ). fbxw7 mutant larvae treated with rapamycin expressed all three genes at lower levels than untreated mutant larvae, although the difference in $m b p$ RNA levels did not reach statistical significance (Fig. $3 S)$. We also tested expression of the cholesterol pathway genes fdps, hmgcra, and hmgcsl and found that both wild-type and fbxw 7 mutant larvae treated with rapamycin expressed these genes at a lower level than corresponding untreated control larvae (Fig. 3T). These data provide evidence that the elevated myelin and cholesterol pathway gene expression of $f b x w 7$ mutant larvae requires mTOR function, consistent with the idea that Fbxw7 limits myelination by negatively regulating mTOR.

If Fbxw7 negatively regulates myelination by limiting the myelin-promoting function of mTOR, then $f b x w 7$ mutant larvae should have elevated levels of mTOR signaling. As an initial test of this prediction, we performed Western blotting of whole larval protein extracts to detect the phosphorylated form of ribosomal protein S6 (phospho-S6), a target of mTOR kinase (Inoki et al., 2002). Compared with wild-type control larvae, phospho-S6 levels were low in extracts from mtor mutant larvae and in extracts from wild-type and $f b x w 7$ mutant larvae treated with rapamycin (Fig. 4A), indicating that this method provides a reliable assessment of mTOR signaling activity. In contrast, phospho-S6 levels in $f b x w 7$ mutant larvae appeared to be higher than in wild-type larvae (Fig. 4A). To investigate whether Fbxw7 regulates mTOR signaling in oligodendrocyte lineage cells, we performed immunohistochemistry to detect phospho-S6 in $\mathrm{Tg}$ (olig2:EGFP) larvae in which OPCs and oligodendrocytes express EGFP under control of olig2 regulatory DNA (Shin et al., 2003). phospho-S6 was evident in numerous cells of $4 \mathrm{dpf}$ wild-type and $f b x w 7$ mutant spinal cords (Fig. $4 B-E^{\prime \prime}$ ). In contrast, wild-type larvae treated with rapamycin had little detectable phospho-S6 (Fig. $4 F-F^{\prime \prime}$ ), validating this method as an assay of mTOR signaling activity. As an initial measurement of mTOR signaling in oligodendrocyte lineage cells, we determined the proportion of olig2:EGFP ${ }^{+}$ OPCs and oligodendrocytes labeled by anti-phospho-S6 antibody by examining single optical sections from confocal image stacks. Whereas $\sim 36 \%$ of olig2:EGFP ${ }^{+}$cells were phospho-S6 ${ }^{+}$ in wild-type larvae, this fraction was increased to $\sim 52 \%$ in $f b x w 7$ mutant larvae and decreased to $\sim 9 \%$ in wild-type larvae treated with rapamycin (Fig. $4 H$ ). To determine whether the increased percentage of phospho-S6 ${ }^{+}$oligodendrocyte lineages cells in fbxw 7 mutants resulted from mTOR activity, we treated them with rapamycin. This reduced the proportion of phospho-S6 ${ }^{+}$ olig2: $\mathrm{EGFP}^{+}$cells to $9 \%$, similar to the fraction in wild-type larvae treated with rapamycin (Fig. 4G,H). We also calculated the relative fluorescence intensity of anti-phospho-S6 antibody

$\leftarrow$

(Figure legend continued.) ${ }^{* *} p<0.01 ; \mathrm{ns}$, no significant difference, unpaired two-tailed Student's $t$ test. Error bars indicate SEM. $\mathbf{C}-\boldsymbol{N}$, Transverse sections of $4 \mathrm{dpf}$ larvae at the level of the trunk spinal cord, with dorsal up, processed for in situ RNA hybridization to detect myelin gene expression. Transcript levels appear reduced in $f b x w 7^{-1-} ; m$ tor ${ }^{-1-}$ larvae $(\boldsymbol{F}, \boldsymbol{J}, \boldsymbol{N})$ relative to $f b x w 7^{-1-}$ larvae $(\boldsymbol{D}, \boldsymbol{H}, \boldsymbol{L}) . \mathbf{O}-\boldsymbol{R}$, Transverse sections through trunk spinal cord processed for immunohistochemistry to detect Mbp. Mbp level in $\mathrm{fbxw} 7^{-1-} ; \mathrm{mtor}^{-1-}$ larva $(\boldsymbol{R})$ is lower than in wild-type $(\mathbf{O})$ and $f$ bxw $7^{-1-}(\boldsymbol{P})$ and similar to $m$ tor $^{-1-}(\mathbf{Q})$. Scale bar, $10 \mu \mathrm{m} . S, T$, Graphs showing relative levels of myelin gene $(\boldsymbol{S})$ and cholesterol pathway gene $(\boldsymbol{T})$ transcripts in $4 \mathrm{dpf}$ wild-type and $f b x w 7$ mutant larvae without $(-)$ or with $(+)$ rapamycin treatment. $n=3$ biological replicates consisting of 20 larvae for each measurement. ${ }^{*} p<0.05$, ${ }^{* *} p<0.01,{ }^{* * *} p<0.005,{ }^{* * * *} p<0.0001$, two-tailed Mann-Whitney test. Error bars indicate SEM. labeling using similarly processed and imaged samples. Although the ranges of intensity values overlapped for individual cells in wild-type and $f b x w 7$ mutant larvae, the average intensity was greater in mutant larvae than in wild-type and in wild-type larvae treated with rapamycin (Fig. $4 I$ ). We conclude that the loss of Fbxw7 function results in elevated mTOR signaling activity in oligodendrocyte lineage cells.

\section{Fbxw7 function in oligodendrocytes limits myelin membrane growth}

Our data show that loss of Fbxw7 function results in elevated levels of mTOR signaling in oligodendrocytes and elevated levels of mTOR-dependent myelination. As a direct test of whether Fbxw7 function in oligodendrocytes limits myelin membrane growth, we expressed either membrane-tethered EGFP (EGFP$\mathrm{CaaX}$ ) alone or a dominant-negative form of Fbxw7 (dnFbxw7) (Hubbard et al., 1997; Mao et al., 2008) and EGFP-CaaX under control of sox10 regulatory DNA, which drives expression in oligodendrocyte lineage cells. Injection into newly fertilized zebrafish eggs using the Tol2 transgenesis system results in expression by a subset of oligodendrocytes, permitting measurement of individual myelin sheath lengths as an indicator of myelin sheath growth (Fig. 5A-D). Oligodendrocytes expressing dnFbxw7 and EGFP-CaaX in wild-type larvae formed myelin sheaths that were, on average, $\sim 23 \%$ longer than those of oligodendrocytes expressing only EGFP-CaaX (Fig. $5 A, B, E$ ). In contrast, myelin sheaths marked by EGFP-CaaX expression were shorter in mtor mutant larvae (Fig. 5C,E), indicating that mTOR promotes sheath extension. To determine whether the excess length of myelin sheaths resulting from dominant-negative Fbxw7 expression requires mTOR function, we expressed dnFbxw7 in oligodendrocytes of mtor mutant larvae. Average sheath length was similar to that of oligodendrocytes in mtor mutants that expressed only the EGFP-CaaX reporter (Fig. $5 D, E$ ), consistent with the idea that Fbxw7 limits myelin sheath length by negatively regulating $\mathrm{mTOR}$ activity.

\section{Discussion}

Oligodendrocyte number, myelin thickness, myelin sheath length, and selection of specific axons for ensheathment are key variables in developmental myelination and remyelination after disease or injury. Identification of molecular mechanisms that regulate these variables is an important goal because mechanistic knowledge should provide insights into the basis of myelin disease and reveal potential targets for remyelinating therapy. $\mathrm{Nu}-$ merous positive and negative regulators of CNS myelination are known (Mitew et al., 2014; Wood et al., 2013), but how these are coordinated to control distinct features of myelination remains poorly understood. Here, we provide new evidence that the myelin-promoting function of mTOR kinase is restricted by the F-box protein Fbxw7.

mTOR activity coordinately controls protein translation and lipid synthesis and thereby promotes cell growth (Laplante and Sabatini, 2012). Therefore, mTOR is well suited to promote formation of large amounts of protein and lipid-rich myelin membrane. Accordingly, oligodendrocyte-specific mutation in mice of Mtor or Raptor, which encodes a subunit of the mTORC1 complex, reduced spinal cord myelination (Bercury et al., 2014; Wahl et al., 2014). Conversely, oligodendrocyte-specific expression of constitutively active Akt drove formation of excess myelin dependent on mTOR function (Flores et al., 2008; Narayanan et al., 2009). Together, these studies indicate that, although mTOR signaling is not solely responsible for CNS myelination, it may be 
A

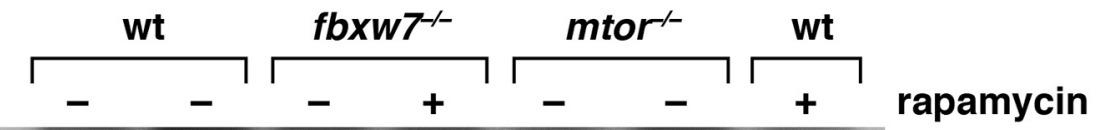

pS6

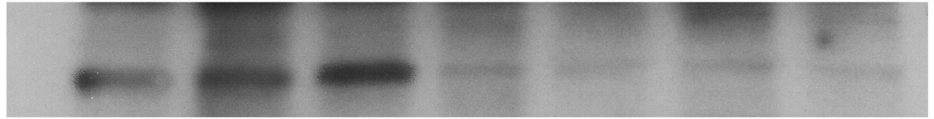

total S6

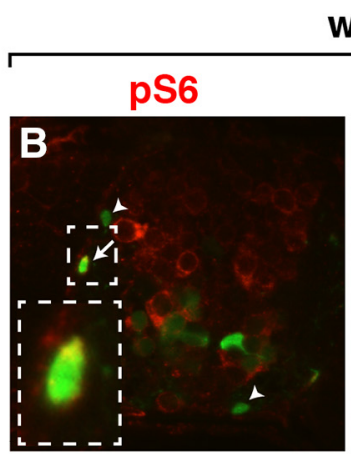

wt

fbxw $7^{-1-}$

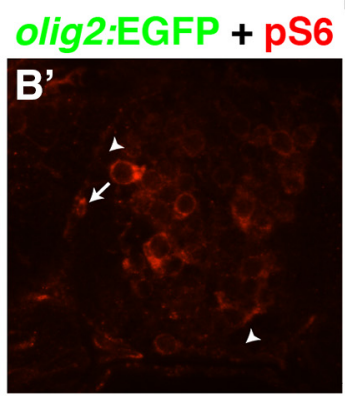
olig2:EGFP + pS6

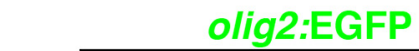

pS6

olig2:EGFP + pS6
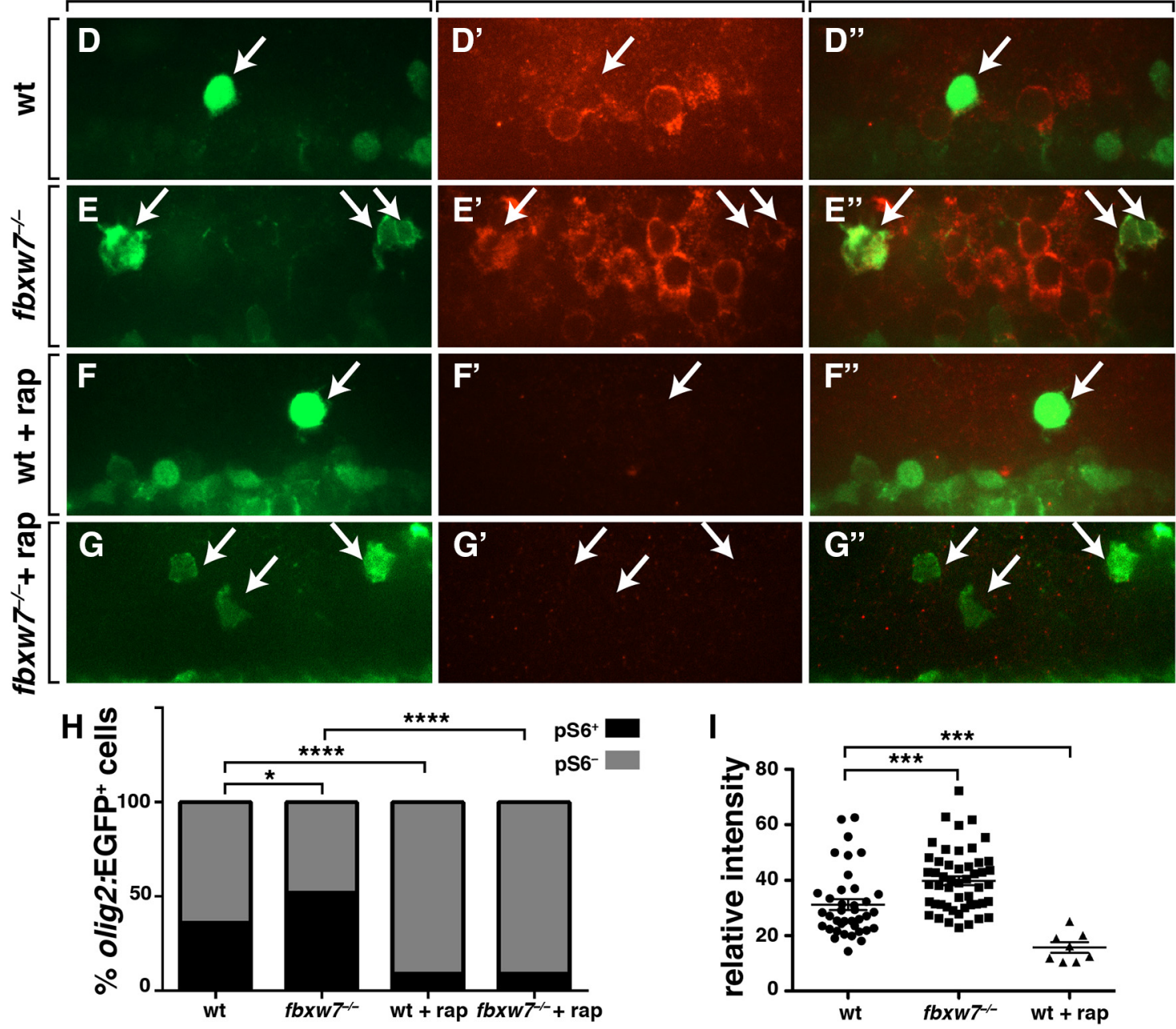

Figure 4. mTOR signaling activity is elevated in $\mathrm{fbxw7}$ mutant larvae. $\boldsymbol{A}$, Western blot showing levels of phospho-S6 (pS6) in extracts obtained from wild-type, fbxw7 mutant, $m$ tor mutant, and wild-type and $f b x w 7$ mutants treated with rapamycin. The blot was also probed to detect total $\mathbf{S 6}$ levels. $\boldsymbol{B}-\boldsymbol{C}^{\prime}$, Representative transverse spinal cord sections of wild-type and fbxw7 mutant larvae carrying the olig2:EGFP transgene and processed for immunohistochemistry to detect phospho-S6. Arrows and arrowheads indicate phospho-S6 ${ }^{+}$and phospho-S6 ${ }^{-}$oligodendrocyte lineage cells, respectively. Outlined boxes show enlarged images of phospho-S6 ${ }^{+}$cells. $\mathbf{D}-\mathbf{G}^{\prime \prime}{ }^{\prime}$, Representative confocal microscope images of spinal cords of whole larvae used for anti-phospho-S6 quantification, dorsal up. Oligodendrocyte lineage cells, marked by olig2:EGFP expression, are indicated by arrows. Treatment with rapamycin eliminated phospho- (Figure legend continues.) 
wt
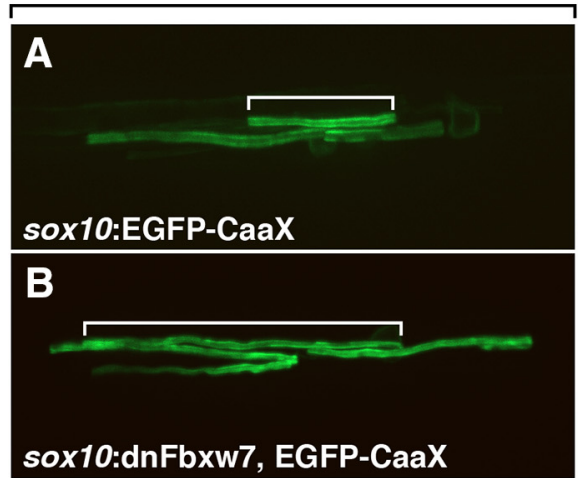

mtor-

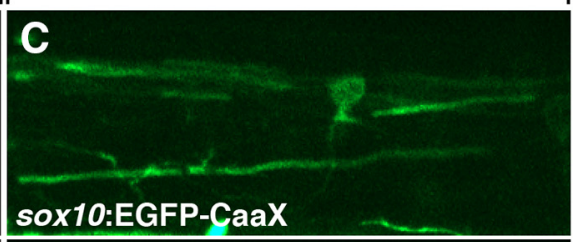

D

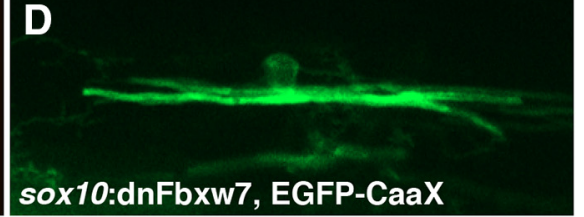

E

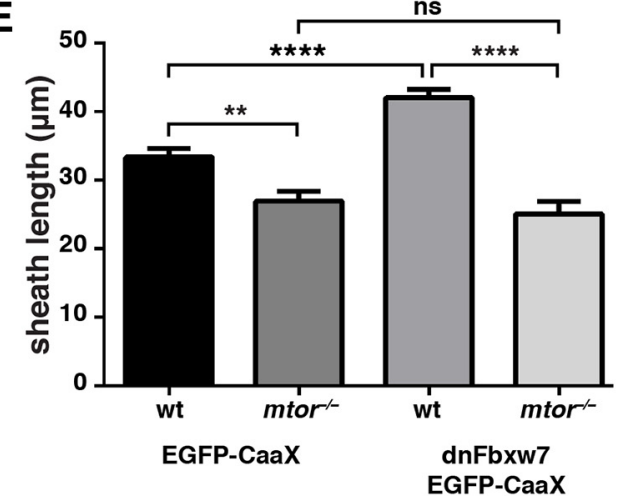

Figure 5. Fbxw7 function limits myelin sheath length. $\boldsymbol{A}-\boldsymbol{D}$, Confocal microscope images of single oligodendrocytes in spinal cords of 6 dpf larvae. Brackets indicate examples of myelin sheaths. Oligodendrocytes in $\boldsymbol{A}$ and $\boldsymbol{C}$ express EGFP-CaaX and those in $\boldsymbol{B}$ and $\boldsymbol{D}$ express dominant-negative Fbxw7 and EGFP-CaaX. $\boldsymbol{E}$, Graph showing average sheath lengths. $n=145$ sheaths from 22 control oligodendrocytes in wild-type larvae, 187 sheaths from $24 \mathrm{dnFbxw7-expressing} \mathrm{oligodendrocytes} \mathrm{in} \mathrm{wild-type} \mathrm{larvae,} 88$ sheaths from 9 control oligodendrocytes in $\mathrm{mtor}^{-1-}$ larvae and 41 sheaths from $3 \mathrm{dnFbxw7-expressing} \mathrm{oligodendrocytes} \mathrm{in}$ mtor $^{-1-}$ larvae. ${ }^{* *} p=0.0012,{ }^{* * * *} p<0.0001$, two-tailed Mann-Whitney test. ns, Not significant.

rate limiting. Because hypermyelination resulting from excessive Akt/mTOR activity is pathogenic (Flores et al., 2008), mechanisms that limit pathway activity in oligodendrocytes might be an important feature of myelination control.

One well characterized negative regulator of mTOR pathway activity is PTEN, a lipid phosphatase that antagonizes PIP3/Akt signaling by converting PIP3 to PIP2. Oligodendrocyte-specific mutation of Pten in mice caused hypermyelination, which appeared to result primarily from increased myelin thickness and not from an increase in oligodendrocyte number (Goebbels et al., 2010; Harrington et al., 2010). Therefore, by limiting PIP3 accumulation, PTEN dampens Akt activation upstream of mTOR and thus limits the formation of myelin membrane.

Our work indicates that Fbxw7 provides an additional level of negative regulation of myelination by limiting both oligodendrocyte number and myelin synthesis. We reported previously that fbxw 7 mutant larvae have a nearly 2 -fold excess of oligodendrocyte cells, which we attributed to elevated Notch signaling (Sny-

(Figure legend continued.) $\mathbf{S} 6$ labeling in wild-type $\left(\boldsymbol{F}-\boldsymbol{F}^{\prime \prime}\right)$ and fbxw7 mutant $\left(\mathbf{G}-\boldsymbol{G}^{\prime \prime}\right)$ larvae. $\mathbf{G}$, Graph showing the relative percentages of phospho- $56^{+}$and phospho- $\mathrm{S}^{-}$olig2:

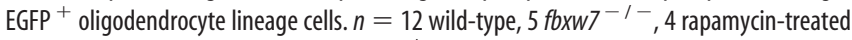
wild-type and 3 rapamycin-treated $f b x w 7^{-1-}$ larvae. ${ }^{*} p=0.0227 ;{ }^{* * * *} p<0.0001$, twosided Fisher's exact test. $\boldsymbol{H}$, Scatter plot showing relative fluorescence intensities of antiphospho-S6 labeling in individual olig2:EGFP ${ }^{+}$oligodendrocyte lineage cells. $n=39$ cells in wild-type, 50 cells in $f b x w 7^{-1-}$ and 8 cells in rapamycin-treated wild-type larvae. ${ }^{* *} p<$ 0.001 , two-sided unpaired $t$ test. der et al., 2012). The intracellular signaling domain of Notch is a known target of Fbxw7 for ubiquitin-mediated degradation (Gupta-Rossi et al., 2001; Oberg et al., 2001; Wu et al., 2001) and conditional expression of constitutively active Notch produced an excess of OPCs (Park and Appel, 2003) that was similar to that of $f b x w 7$ loss of function. Time-lapse imaging showed that excess OPCs migrated from their ventral spinal cord origin but did not subsequently divide more frequently than OPCs in wild-type larvae, indicating that overproduction of OPCs in $f b x w 7$ mutant larvae results from specification of excess neural precursors for oligodendrocyte fate rather than from excessive proliferation of oligodendrocyte progenitors (Snyder et al., 2012). Pharmacological inhibition of Notch signaling suppressed formation of excess OPCs in fbxw7 mutant larvae (Snyder et al., 2012), providing evidence that misregulated Notch signaling is primarily responsible for the excess OPC phenotype. In this study, we found that loss of mTOR function also had an effect on oligodendrocyte lineage cell number whereby both mtor mutant larvae and wild-type larvae treated with rapamycin had slightly fewer oligodendrocyte lineage cells than wildtype control larvae. Notably, loss of mTOR function had a more pronounced effect on $f b x w 7$ mutant larvae, reducing oligodendrocyte lineage cell numbers to nearly normal levels. We think that these observations reveal a role for $\mathrm{mTOR}$ in OPC proliferation and not OPC specification. Treatment with rapamycin beginning at $72 \mathrm{hpf}$ after OPC formation resulted in a smaller increase in cell number $1 \mathrm{~d}$ later than in control larvae. We found no evidence for a difference in cell death using activated Caspase 3 immunohistochemistry, suggesting that mTOR promotes OPC proliferation between 3 and $4 \mathrm{dpf}$. Consistent with this, mTOR can promote OPC proliferation in response to growth factors in culture (Gomez et al., 2015). In addition, Fbxw7 mutation sensitizes cancer cells to rapamycin, apparently by increasing the efficiency of cell killing by rapamycin (Mao et al., 2008). The mechanism by which this occurs is not known. In rodents, oligodendrocyte number is regulated by limiting amounts of growth factors, particularly PDGF (Calver et al., 1998; Fruttiger et al., 1999). We speculate that elevated mTOR function in $f b x w 7$ mutant larvae enhances cell proliferation and possibly viability when growth factors are limiting, supporting an enlarged oligodendrocyte population.

Our work also provides evidence that Fbxw7 regulates myelin gene expression and myelin membrane growth by modulating mTOR signaling. Our observation that oligodendrocytes of $f b x w 7$ mutant larvae express myelin genes was initially confounding because Notch signaling inhibits myelination (Wang et al., 1998; Genoud et al., 2002; Givogri et al., 2002; John et al., 2002; Park and Appel, 2003) and most known Fbxw7 targets function in cell proliferation (Welcker and Clurman, 2008). However, the identification of mTOR as a Fbxw7 target in cancer cells (Mao et al., 2008) and the mounting evidence that mTOR drives CNS 
myelination (Tyler et al., 2009; Bercury et al., 2014; Wahl et al., 2014) raised the possibility that elevated mTOR activity overcomes Notch-mediated inhibition of myelination in $f b x w 7 \mathrm{mu}-$ tant larvae. In support of this, mTOR function was required for the elevated levels of myelin gene expression in fbxw7 mutant larvae, the mTOR signaling pathway was active at higher level in more oligodendrocyte lineage cells of $f b x w 7$ mutant larvae relative to control larvae, $f b x w 7$ mutant larvae formed more myelin membrane wraps on axons than wild-type, and oligodendrocytes expressing a dominant-negative Fbxw7 had longer myelin sheaths.

Our data also raise the possibility that Fbxw7 control of mTOR signaling influences the differentiation status of nonmyelinating OPCs. fbxw7 mutant larvae ectopically expressed the myelin-associated genes plpla and cldnk in medial spinal cord, which is normally occupied by Sox $10^{+}$oligodendrocyte lineage cells that do not express markers of mature oligodendrocytes. Ectopic plpla and cldnk expression was dependent on mTOR function because it was absent from medial spinal cords of $f b x w 7$ mutant larvae treated with rapamycin or homozygous for a $m$ tor mutation. One potential explanation for these observations is that Fbxw7 inhibition of mTOR helps to maintain the nonmyelinating state of a subset of oligodendrocyte lineage cells during development. However, we never detected ectopic expression of $m b p$ in $f b x w 7$ mutant larvae, indicating that reduction of Fbxw7 function is not sufficient for OPCs to fully differentiate as myelinating oligodendrocytes.

Could Fbxw7 tune mTOR activity to modulate the amount of myelin formed during development? Fbxw7 binds to its substrates at a conserved, phospho-threonine containing motif called the Cdc4 phospho-degron (CPD) (Nash et al., 2001). Substrate binding and degradation requires phosphorylation of the $\mathrm{CPD}$, raising the possibility that developmentally controlled phosphorylation of the mTOR CPD regulates the myelinpromoting activity of mTOR. The central threonine of most, if not all, CPDs is phosphorylated by glycogen synthase kinase 3 (GSK3) (Welcker and Clurman, 2008). Therefore, GSK3mediated phosphorylation of the mTOR CPD might suppress myelination. Notably, inhibition of GSK3 $\beta$ in rodents stimulated OPC proliferation, supported oligodendrocyte lineage cell survival, and promoted myelination (Azim and Butt, 2011). These effects were attributed to changes in cAMP response element binding and Notch signaling. Our study now indicates that GSK3 $\beta$ inhibition might also promote myelination by decreasing the amount of mTOR targeted for degradation by Fbxw7.

\section{References}

Azim K, Butt AM (2011) GSK3 $\beta$ negatively regulates oligodendrocyte differentiation and myelination in vivo. Glia 59:540-553. CrossRef Medline

Bercury KK, Dai J, Sachs HH, Ahrendsen JT, Wood TL, Macklin WB (2014) Conditional Ablation of Raptor or Rictor Has Differential Impact on Oligodendrocyte Differentiation and CNS Myelination. J Neurosci 34: 4466-4480. CrossRef Medline

Brinkmann BG, Agarwal A, Sereda MW, Garratt AN, Müller T, Wende H, Stassart RM, Nawaz S, Humml C, Velanac V, Radyushkin K, Goebbels S, Fischer TM, Franklin RJ, Lai C, Ehrenreich H, Birchmeier C, Schwab MH, Nave KA (2008) Neuregulin-1/ErbB signaling serves distinct functions in myelination of the peripheral and central nervous system. Neuron 59:581-595. CrossRef Medline

Brösamle C, Halpern ME (2002) Characterization of myelination in the developing zebrafish. Glia 39:47-57. CrossRef Medline

Calver AR, Hall AC, Yu WP, Walsh FS, Heath JK, Betsholtz C, Richardson WD (1998) Oligodendrocyte population dynamics and the role of PDGF in vivo. Neuron 20:869-882. CrossRef Medline

Carney TJ, Dutton KA, Greenhill E, Delfino-Machín M, Dufourcq P, Blader
P, Kelsh RN (2006) A direct role for Sox10 in specification of neural crest-derived sensory neurons. Development 133:4619-4630. CrossRef Medline

Carson MJ, Behringer RR, Brinster RL, McMorris FA (1993) Insulin-like growth factor I increases brain growth and central nervous system myelination in transgenic mice. Neuron 10:729-740. CrossRef Medline

Ding Y, Sun X, Huang W, Hoage T, Redfield M, Kushwaha S, Sivasubbu S, Lin X, Ekker S, Xu X (2011) Haploinsufficiency of target of rapamycin attenuates cardiomyopathies in adult zebrafish. Circ Res 109:658-669. CrossRef Medline

Flores AI, Narayanan SP, Morse EN, Shick HE, Yin X, Kidd G, Avila RL, Kirschner DA, Macklin WB (2008) Constitutively active Akt induces enhanced myelination in the CNS. J Neurosci 28:7174-7183. CrossRef Medline

Fruttiger M, Karlsson L, Hall AC, Abramsson A, Calver AR, Boström H, Willetts K, Bertold CH, Heath JK, Betsholtz C, Richardson WD (1999) Defective oligodendrocyte development and severe hypomyelination in PDGF-A knockout mice. Development 126:457-467. Medline

Genoud S, Lappe-Siefke C, Goebbels S, Radtke F, Aguet M, Scherer SS, Suter U, Nave KA, Mantei N (2002) Notch1 control of oligodendrocyte differentiation in the spinal cord. J Cell Biol 158:709-718. CrossRef Medline

Givogri MI, Costa RM, Schonmann V, Silva AJ, Campagnoni AT, Bongarzone ER (2002) Central nervous system myelination in mice with deficient expression of Notch1 receptor. J Neurosci Res 67:309-320. CrossRef Medline

Goddard DR, Berry M, Butt AM (1999) In vivo actions of fibroblast growth factor-2 and insulin-like growth factor-I on oligodendrocyte development and myelination in the central nervous system. J Neurosci Res 57: 74-85. CrossRef Medline

Goebbels S, Oltrogge JH, Kemper R, Heilmann I, Bormuth I, Wolfer S, Wichert SP, Möbius W, Liu X, Lappe-Siefke C, Rossner MJ, Groszer M, Suter U, Frahm J, Boretius S, Nave KA (2010) Elevated phosphatidylinositol 3,4,5-trisphosphate in glia triggers cell-autonomous membrane wrapping and myelination. J Neurosci 30:8953-8964. CrossRef Medline

Gomez O, Sanchez-Rodriguez MA, Ortega-Gutierrez S, Vazquez-Villa H, Guaza C, Molina-Holgado F, Molina-Holgado E (2015) A basal tone of 2 -arachidonoylglycerol contributes to early oligodendrocyte progenitor proliferation by activating phosphatidylinositol 3-kinase (PI3K)/AKT and the mammalian target of rapamycin (MTOR) pathways. J Neuroimmune Pharmacol 10:309-317. CrossRef Medline

Guardiola-Diaz HM, Ishii A, Bansal R (2012) Erk1/2 MAPK and mTOR signaling sequentially regulates progression through distinct stages of oligodendrocyte differentiation. Glia 60:476-486. CrossRef Medline

Gupta-Rossi N, Le Bail O, Gonen H, Brou C, Logeat F, Six E, Ciechanover A, Israël A (2001) Functional interaction between SEL-10, an F-box protein, and the nuclear form of activated Notch1 receptor. J Biol Chem 276:34371-34378. CrossRef Medline

Harrington EP, Zhao C, Fancy SPJ, Kaing S, Franklin RJ, Rowitch DH (2010) Oligodendrocyte PTEN is required for myelin and axonal integrity, not remyelination. Ann Neurol 68:703-716. CrossRef Medline

Hauptmann G, Gerster T (2000) Multicolor whole-mount in situ hybridization. Methods Mol Biol 137:139-148. Medline

Horrocks LA (1967) Composition of myelin from peripheral and central nervous systems of the squirrel monkey. J Lipid Res 8:569-576. Medline

Hubbard EJ, Wu G, Kitajewski J, Greenwald I (1997) sel-10, a negative regulator of lin-12 activity in Caenorhabditis elegans, encodes a member of the CDC4 family of proteins. Genes Dev 11:3182-3193. CrossRef Medline

Inoki K, Li Y, Zhu T, Wu J, Guan KL (2002) TSC2 is phosphorylated and inhibited by Akt and suppresses mTOR signalling. Nat Cell Biol 4:648657. CrossRef Medline

John GR, Shankar SL, Shafit-Zagardo B, Massimi A, Lee SC, Raine CS, Brosnan CF (2002) Multiple sclerosis: re-expression of a developmental pathway that restricts oligodendrocyte maturation. Nat Med 8:11151121. CrossRef Medline

Kimmel CB, Ballard WW, Kimmel SR, Ullmann B, Schilling TF (1995) Stages of embryonic development of the zebrafish. Dev Dyn 203:253-310. CrossRef Medline

Kucenas S, Wang WD, Knapik EW, Appel B (2009) A selective glial barrier at motor axon exit points prevents oligodendrocyte migration from the spinal cord. J Neurosci 29:15187-15194. CrossRef Medline

Kwan KM, Fujimoto E, Grabher C, Mangum BD, Hardy ME, Campbell DS, Parant JM, Yost HJ, Kanki JP, Chien CB (2007) The Tol2kit: a multisite 
gateway-based construction kit for Tol2 transposon transgenesis constructs. Dev Dyn 236:3088-3099. CrossRef Medline

Langworthy MM, Appel B (2012) Schwann cell myelination requires Dynein function. Neural Dev 7:37. CrossRef Medline

Laplante M, Sabatini DM (2012) mTOR signaling in growth control and disease. Cell 149:274-293. CrossRef Medline

Lebrun-Julien F, Bachmann L, Norrmén C, Trötzmüller M, Köfeler H, Rüegg MA, Hall MN, Suter U (2014) Balanced mTORC1 Activity in Oligodendrocytes Is Required for Accurate CNS Myelination. J Neurosci 34:84328448. CrossRef Medline

Makinodan M, Rosen KM, Ito S, Corfas G (2012) A critical period for social experience-dependent oligodendrocyte maturation and myelination. Science 337:1357-1360. CrossRef Medline

Mao JH, Kim IJ, Wu D, Climent J, Kang HC, DelRosario R, Balmain A (2008) FBXW7 targets mTOR for degradation and cooperates with PTEN in tumor suppression. Science 321:1499-1502. CrossRef Medline

Mitew S, Hay CM, Peckham H, Xiao J, Koenning M, Emery B (2014) Mechanisms regulating the development of oligodendrocytes and central nervous system myelin. Neuroscience 276:29-47. Medline

Narayanan SP, Flores AI, Wang F, Macklin WB (2009) Akt signals through the mammalian target of rapamycin pathway to regulate CNS myelination. J Neurosci 29:6860-6870. CrossRef Medline

Nash P, Tang X, Orlicky S, Chen Q, Gertler FB, Mendenhall MD, Sicheri F, Pawson T, Tyers M (2001) Multisite phosphorylation of a CDK inhibitor sets a threshold for the onset of DNA replication. Nature 414:514-521. CrossRef Medline

Oberg C, Li J, Pauley A, Wolf E, Gurney M, Lendahl U (2001) The Notch intracellular domain is ubiquitinated and negatively regulated by the mammalian Sel-10 homolog. J Biol Chem 276:35847-35853. CrossRef Medline

Park HC, Appel B (2003) Delta-Notch signaling regulates oligodendrocyte specification. Development 130:3747-3755. CrossRef Medline

Park HC, Boyce J, Shin J, Appel B (2005) Oligodendrocyte specification in zebrafish requires notch-regulated cyclin-dependent kinase inhibitor function. J Neurosci 25:6836-6844. CrossRef Medline

Shin J, Park HC, Topczewska JM, Mawdsley DJ, Appel B (2003) Neural cell fate analysis in zebrafish using olig2 BAC transgenics. Methods Cell Sci 25:7-14. CrossRef Medline

Snyder JL, Kearns CA, Appel B (2012) Fbxw7 regulates Notch to control specification of neural precursors for oligodendrocyte fate. Neural Dev 7:15. CrossRef Medline

Takada N, Appel B (2010) Identification of genes expressed by zebrafish oligodendrocytes using a differential microarray screen. Dev Dyn 239: 2041-2047. CrossRef Medline

Tyler WA, Gangoli N, Gokina P, Kim HA, Covey M, Levison SW, Wood TL (2009) Activation of the mammalian target of rapamycin (mTOR) is essential for oligodendrocyte differentiation. J Neurosci 29:6367-6378. CrossRef Medline

Tyler WA, Jain MR, Cifelli SE, Li Q, Ku L, Feng Y, Li H, Wood TL (2011) Proteomic identification of novel targets regulated by the mammalian target of rapamycin pathway during oligodendrocyte differentiation. Glia 59:1754-1769. CrossRef Medline

Wahl SE, McLane LE, Bercury KK, Macklin WB, Wood TL (2014) Mammalian target of rapamycin promotes oligodendrocyte differentiation, initiation and extent of CNS myelination. J Neurosci 34:4453-4465. CrossRef Medline

Wang S, Sdrulla AD, diSibio G, Bush G, Nofziger D, Hicks C, Weinmaster G, Barres BA (1998) Notch receptor activation inhibits oligodendrocyte differentiation. Neuron 21:63-75. CrossRef Medline

Welcker M, Clurman BE (2008) FBW7 ubiquitin ligase: a tumour suppressor at the crossroads of cell division, growth and differentiation. Nat Rev Cancer 8:83-93. CrossRef Medline

Wood TL, Bercury KK, Cifelli SE, Mursch LE, Min J, Dai J, Macklin WB (2013) mTOR: a link from the extracellular milieu to transcriptional regulation of oligodendrocyte development. ASN Neuro 5:e00108.

Wu G, Lyapina S, Das I, Li J, Gurney M, Pauley A, Chui I, Deshaies RJ, Kitajewski J (2001) SEL-10 is an inhibitor of notch signaling that targets notch for ubiquitin-mediated protein degradation. Mol Cell Biol 21: 7403-7415. CrossRef Medline

Ye P, Li L, Richards RG, DiAugustine RP, D'Ercole AJ (2002) Myelination is altered in insulin-like growth factor-I-null mutant mice. J Neurosci 22: 6041-6051. Medline 